University of Wollongong

Research Online

Australian Institute for Innovative Materials -

Papers

Australian Institute for Innovative Materials

$1-1-2014$

\title{
PMN-PT based quaternary piezoceramics with enhanced piezoelectricity and temperature stability
}

Nengneng Luo

Tsinghua University

Shujun Zhang

Pennsylvania State University, shujun@uow.edu.au

Qiang Li

Tsinghua University

Qingfeng Yan

Tsinghua University

Wenhui He

Tsinghua University

See next page for additional authors

Follow this and additional works at: https://ro.uow.edu.au/aiimpapers

Part of the Engineering Commons, and the Physical Sciences and Mathematics Commons

Research Online is the open access institutional repository for the University of Wollongong. For further information contact the UOW Library: research-pubs@uow.edu.au 


\title{
PMN-PT based quaternary piezoceramics with enhanced piezoelectricity and temperature stability
}

\author{
Abstract \\ The phase structure, piezoelectric, dielectric, and ferroelectric properties of \\ (0.80-x)PMN-0.10PFN-0.10PZ-xPT were investigated systematically. The morphotropic phase boundary \\ (MPB) was confirmed to be 0.30

\section{Keywords} \\ piezoelectricity, enhanced, stability, piezoceramics, temperature, quaternary, pt, pmn \\ Disciplines \\ Engineering | Physical Sciences and Mathematics \\ Publication Details \\ Luo, N., Zhang, S., Li, Q., Yan, Q., He, W., Zhang, Y. \& Shrout, T. R. (2014). PMN-PT based quaternary \\ piezoceramics with enhanced piezoelectricity and temperature stability. Applied Physics Letters, 104 (18), \\ 182911-1-182911-5.

\section{Authors} \\ Nengneng Luo, Shujun Zhang, Qiang Li, Qingfeng Yan, Wenhui He, Yiling Zhang, and Thomas R. Shrout
}




\section{AIP Anoled phyises \\ Letters}

\section{PMN-PT based quaternary piezoceramics with enhanced piezoelectricity and temperature stability}

Nengneng Luo, Shujun Zhang, Qiang Li, Qingfeng Yan, Wenhui He, Yiling Zhang, and Thomas R Shrout

Citation: Applied Physics Letters 104, 182911 (2014); doi: 10.1063/1.4875797

View online: http://dx.doi.org/10.1063/1.4875797

View Table of Contents: http://scitation.aip.org/content/aip/journal/apl/104/18?ver=pdfcov

Published by the AIP Publishing

\section{Articles you may be interested in}

Enhanced dielectric, ferroelectric, and electrostrictive properties of $\mathrm{Pb}(\mathrm{Mg} 1 / 3 \mathrm{Nb} 2 / 3) 0.9 \mathrm{Ti} 0.103$ ceramics by $\mathrm{ZnO}$ modification

J. Appl. Phys. 113, 204101 (2013); 10.1063/1.4801881

The study of dielectric, pyroelectric and piezoelectric properties on hot pressed PZT-PMN systems AIP Advances 2, 042170 (2012); 10.1063/1.4769889

Structure, piezoelectric, and ferroelectric properties of $\mathrm{BaZrO} 3$ substituted $\mathrm{Bi}(\mathrm{Mg} 1 / 2 \mathrm{Ti} 1 / 2) \mathrm{O} 3-\mathrm{PbTiO} 3$ perovskite J. Appl. Phys. 111, 104118 (2012); 10.1063/1.4722286

Piezoelectric properties and temperature stability of Mn-doped $\mathrm{Pb}(\mathrm{Mg} 1 / 3 \mathrm{Nb} 2 / 3)-\mathrm{PbZrO} 3-\mathrm{PbTiO} 3$ textured ceramics

Appl. Phys. Lett. 100, 132908 (2012); 10.1063/1.3698157

High temperature properties of $\mathrm{BiScO} 3-\mathrm{PbTiO} 3$ piezoelectric ceramics

J. Appl. Phys. 106, 014102 (2009); 10.1063/1.3158542

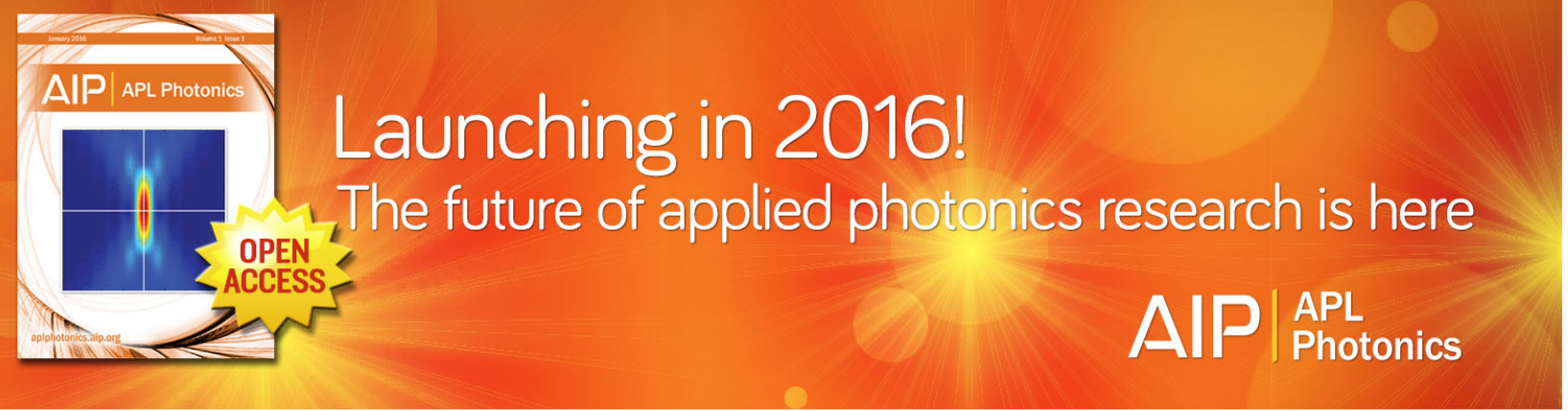




\title{
PMN-PT based quaternary piezoceramics with enhanced piezoelectricity and temperature stability
}

\author{
Nengneng Luo, ${ }^{1,2}$ Shujun Zhang, ${ }^{2}$ Qiang Li, ${ }^{1, a)}$ Qingfeng Yan, ${ }^{1}$ Wenhui He, ${ }^{1}$ Yiling Zhang, ${ }^{3}$ \\ and Thomas R Shrout ${ }^{2}$ \\ ${ }^{1}$ Department of Chemistry, Tsinghua University, Beijing 100084, China \\ ${ }^{2}$ Materials Research Institute, Pennsylvania State University, University Park, Pennsylvania 16802, USA \\ ${ }^{3}$ School of Materials Science \& Engineering, Tsinghua University, Beijing 100084, China
}

(Received 5 March 2014; accepted 28 April 2014; published online 9 May 2014)

\begin{abstract}
The phase structure, piezoelectric, dielectric, and ferroelectric properties of $(0.80-\mathrm{x}) \mathrm{PMN}$ 0.10PFN-0.10PZ-xPT were investigated systematically. The morphotropic phase boundary (MPB) was confirmed to be $0.30<\mathrm{x}<0.34$. Both MPB compositions of $\mathrm{x}=0.32$ and $\mathrm{x}=0.33$ exhibit high piezoelectric coefficients $d_{33}=640 \mathrm{pC} / \mathrm{N}$ and $580 \mathrm{pC} / \mathrm{N}$, electromechanical couplings $k_{\mathrm{p}}$ of 0.53 and 0.52 , respectively. Of particular importance is that the composition with $\mathrm{x}=0.33$ was found to process high field-induced piezoelectric strain coefficient $d_{33} *$ of $680 \mathrm{pm} / \mathrm{V}$, exhibiting a minimal temperature-dependent behavior, being less than $8 \%$ in the temperature range of $25-165^{\circ} \mathrm{C}$, which can be further confirmed by $d_{31}$, with a variation of less than $9 \%$. The temperature-insensitive $d_{33} *$ values can be explained by the counterbalance of the ascending dielectric permittivity and descending polarization with increasing temperature. These features make the PMN-PT based quaternary MPB compositions promising for actuator applications demanding high temperature stability. C 2014 AIP Publishing LLC. [http://dx.doi.org/10.1063/1.4875797]
\end{abstract}

Lead-based relaxor ferroelectric materials with perovskite structure have been actively investigated since 1970 s due to their good electromechanical properties, among which, $\mathrm{Pb}\left(\mathrm{Mg}_{1 / 3} \mathrm{Nb}_{2 / 3}\right) \mathrm{O}_{3}-\mathrm{PbTiO}_{3}$ (PMN-PT) was reported to process extra high electromechanical coupling factor and piezoelectric coefficient, making it one of the most promising candidates for piezoelectric actuator, sensor, and transducer applications. ${ }^{1-3}$ Generally, the enhanced electromechanical properties can be obtained at morphotropic phase boundary (MPB) region. ${ }^{4,5}$ However, the applications of the PMN-PT ferroelectric materials with MPB compositions are limited by the loss of temperature stability, because of the relatively low Curie temperature $\left(T_{\mathrm{c}} \sim 130-170^{\circ} \mathrm{C}\right)$ and much lower rhombohedral to tetragonal ferroelectric phase transition temperature $\left(T_{\mathrm{rt}} \sim 50-85^{\circ} \mathrm{C}\right)$ due to the strongly curved MPB. Therefore, over the past few years, tremendous efforts have been made to improve the temperature stability of the properties, two potential approaches have been adopted so far: shifting $T_{\mathrm{c}} / T_{\mathrm{rt}}$ to higher temperature by composition tuning, and taking advantage of the engineered domain configuration in single crystals. ${ }^{3}$ In the first method, through elements substituting and/or adding of other end-members, numerous new higher $T_{\mathrm{c}} / T_{\mathrm{rt}}$ binary and ternary material systems were developed, including $\mathrm{Pb}\left(\mathrm{In}_{1 / 2} \mathrm{Nb}_{1 / 2}\right)-\mathrm{PbTiO}_{3} \quad$ (PIN-PT), ${ }^{6,7}$ $\mathrm{Pb}\left(\mathrm{Yb}_{1 / 2} \mathrm{Nb}_{1 / 2}\right)-\mathrm{PbTiO}_{3}$ (PYN-PT), ${ }^{8,9} \mathrm{~Pb}\left(\mathrm{Sc}_{1 / 2} \mathrm{Nb}_{1 / 2}\right)-\mathrm{PbTiO}_{3}$ (PSN-PT) ${ }^{10} \quad \mathrm{~Pb}\left(\mathrm{In}_{1 / 2} \mathrm{Nb}_{1 / 2}\right)-\mathrm{Pb}\left(\mathrm{Mg}_{1 / 3} \mathrm{Nb}_{2 / 3}\right) \mathrm{O}_{3}-\mathrm{PbTiO}_{3}$ (PIN-PMN-PT), ${ }^{11-15} \quad \mathrm{~Pb}\left(\mathrm{Mg}_{1 / 3} \mathrm{Nb}_{2 / 3}\right) \mathrm{O}_{3}-\mathrm{PbZrO}_{3}-\mathrm{PbTiO}_{3}$ (PMN-PZ-PT), ${ }^{16-19}$ and $\mathrm{Pb}\left(\mathrm{Sc}_{1 / 2} \mathrm{Nb}_{1 / 2}\right)-\mathrm{Pb}\left(\mathrm{Mg}_{1 / 3} \mathrm{Nb}_{2 / 3}\right) \mathrm{O}_{3}-\mathrm{PbTiO}_{3}$ (PSN-PMN-PT), ${ }^{20}$ etc. However, it was found that the temperature stability remained unsolved despite of the high $T_{\mathrm{c}} / T_{\mathrm{rt}}$. Take PIN-PMN-PT ceramics for example, the variation of $d_{33}$

\footnotetext{
a) Author to whom correspondence should be addressed. Electronic mail: qiangli@mail.tsinghua.edu.cn. Tel.: +86-10-62797871. Fax: +86-1062771149 .
}

was reported to be $\sim 20 \%$ at $150{ }^{\circ} \mathrm{C}$ when compared with that at room temperature. ${ }^{13}$ It was expected that the $\mathrm{Bi}(\mathrm{Me}) \mathrm{O}_{3^{-}}$ $\mathrm{PbTiO}_{3}$ compositions with higher $T_{\mathrm{c}}>300^{\circ} \mathrm{C}$ will shed light on the potentiality of achieving high temperature stability. ${ }^{21-26}$ However, except $\mathrm{BiScO}_{3}-\mathrm{PbTiO}_{3}$ (BS-PT), ${ }^{21}$ the piezoelectric coefficients of the reported $\mathrm{Bi}(\mathrm{Me}) \mathrm{O}_{3}-\mathrm{PbTiO}_{3}$ based ceramics, such as $\mathrm{BiFeO}_{3}-\mathrm{PbTiO}_{3}$ (BF-PT), ${ }^{22} \mathrm{BiInO}_{3}-\mathrm{PbTiO}_{3}$ (BI-PT), ${ }^{23}$ $\mathrm{Bi}\left(\mathrm{Ni}_{1 / 2} \mathrm{Ti}_{1 / 2}\right) \mathrm{O}_{3}-\mathrm{PbTiO}_{3} \quad$ (BNT-PT $),{ }^{24} \mathrm{Bi}\left(\mathrm{Mg}_{1 / 2} \mathrm{Ti}_{1 / 2}\right) \mathrm{O}_{3^{-}}$ $\mathrm{PbTiO}_{3}$ (BMT-PT), ${ }^{25,26}$ etc., were lower than $300 \mathrm{pC} / \mathrm{N}$ at their respective MPBs. Furthermore, it was reported that piezoelectric coefficients exhibited different degree of degradation in binary and ternary systems, not necessarily associated with their $T_{\mathrm{c}} / T_{\mathrm{rt}}$, though higher $T_{\mathrm{c}}$ indicating broader usage temperature range. ${ }^{27}$ In the second method, investigations were focused on preparing single crystals with engineered domain configurations, where greatly enhanced piezoelectric $d_{33}$ was obtained taking advantage of the crystallographic anisotropy. Nevertheless, the longitudinal piezoelectric coefficient $d_{33}$ still exhibited large temperature-dependent variation when MPB compositions were selected. ${ }^{9,12,14,17,18,28}$ Of particular significance is that the thickness shear piezoelectric $d_{24}$ in [011]-poled orthorhombic relaxor- $\mathrm{PbTiO}_{3}$ crystals was reported to possess excellent temperature stability with high value being on the order of $\sim 2100 \mathrm{pC} / \mathrm{N}$, due to the vertical R-O MPB. ${ }^{15,29}$ However, the complex synthesis or growth method is too expensive to enable mass production and commercialization. As a result, the development of high performance piezoelectric materials is still hampered due to the insufficient temperature stability.

For polycrystalline ceramics, a multiple end-members system may help adjusting the properties of materials more efficiently, taking advantage of each end-member. It was noted that most PMN-PT based ternary systems generally exhibited improved comprehensive performance when compared with that of binary systems, such as higher $T_{\mathrm{rt}}$ with comparable 


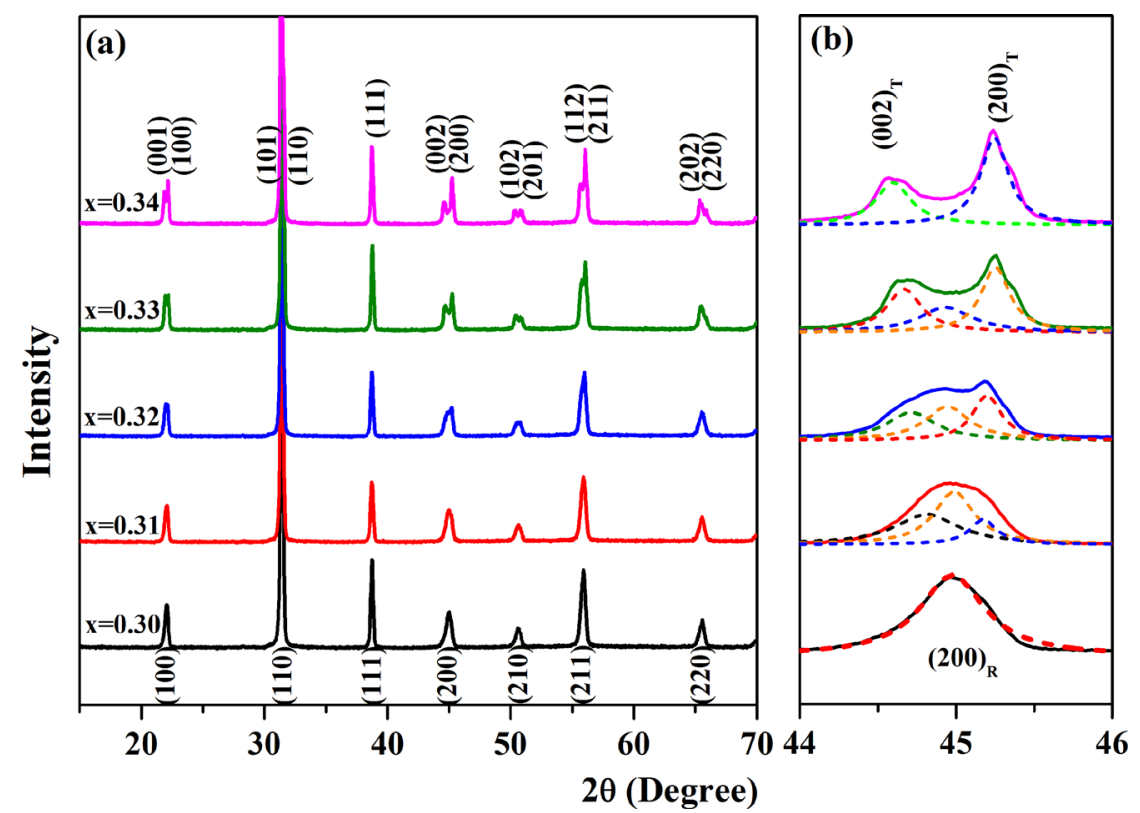

FIG. 1. XRD patterns of the assintered PMN-PFN-PZ-PT ceramics. (a) $2 \theta=15^{\circ}-70^{\circ}$, (b) (200)-reflections at $2 \theta=44^{\circ}-46^{\circ}$. piezoelectric properties. ${ }^{11-20,30}$ The PMN- PZ-PT ternary system, which can be regarded as the combination of PMN-PT and PZT, was reported to possess high ferroelectric phase transition temperatures and high coercive fields, the as-grown PMN-PZ-PT single crystals were considered to be the second generation relaxor-PT crystals. ${ }^{3} \mathrm{~Pb}\left(\mathrm{Fe}_{1 / 2} \mathrm{Nb}_{1 / 2}\right) \mathrm{O}_{3}$ (PFN) is a typical relaxor ferroelectric material with high dielectric permittivity. Through the hybridization of PMN-PT, PZT, and $\mathrm{PFN}$, a quaternary system $(0.85-\mathrm{x}) \mathrm{Pb}\left(\mathrm{Mg}_{1 / 3} \mathrm{Nb}_{2 / 3}\right) \mathrm{O}_{3}-0.10 \mathrm{~Pb}$ $\left(\mathrm{Fe}_{1 / 2} \mathrm{Nb}_{1 / 2}\right) \mathrm{O}_{3}-0.05 \mathrm{PbZrO}_{3}-\mathrm{xPbTiO}_{3} \quad$ (PMN-PFN-PZ-PT) was reported with high $d_{33}>600 \mathrm{pC} / \mathrm{N}$ and enhanced ferroelectric phase transition temperature. ${ }^{31}$

In this work, by tuning the amount of $\mathrm{PZ}$ end-member, a quaternary system $(0.80-\mathrm{x}) \mathrm{Pb}\left(\mathrm{Mg}_{1 / 3} \mathrm{Nb}_{2 / 3}\right) \mathrm{O}_{3}-0.10 \mathrm{~Pb}$ $\left(\mathrm{Fe}_{1 / 2} \mathrm{Nb}_{1 / 2}\right) \mathrm{O}_{3}-0.10 \mathrm{PbZrO}_{3}-\mathrm{xPbTiO}_{3}$ at $\mathrm{MPB}$ region was explored, which exhibited enhanced piezoelectricity and high temperature stability from room temperature to $165^{\circ} \mathrm{C}$. The mechanism of temperature stable piezoelectric response was explained, pioneering new approach of developing temperature-insensitive piezoelectric actuators.

(0.80 - x)PMN-0.10PFN-0.10PZ-xPT ceramics with $\mathrm{x}=0.30-0.34$ were prepared by conventional solid state reaction, following the procedure reported earlier. ${ }^{31}$ Disk and bar samples with electrodes on the large faces were prepared for the electric properties measurement, as described in the IEEE Standards. ${ }^{32}$ The crystal structure of the assintered samples was determined using an X-ray diffractometer (D8 ADVANCE, Brüker, German) with $\mathrm{Cu} \mathrm{K}_{\alpha}$ radiation at $2 \theta$ from $15^{\circ}$ to $70^{\circ}$. The temperature dependence of dielectric properties were measured at $1 \mathrm{kHz}$ using an Agilent 4294A (Agilent Inc., Bayan, Malaysia) impedance analyzer connected to a Delta 9023 (Delta Design Inc., San Diego, America) temperature control system. All samples were poled under $3 \mathrm{kV} / \mathrm{mm}$ DC field at $120^{\circ} \mathrm{C}$ for $15 \mathrm{~min}$ in silicon oil. Room temperature piezoelectric coefficient $d_{33}$ of disk samples were measured using a quasi-static piezo- $d_{33}$ meter (ZJ-4A, Institute of Acoustics, Chinese Academy of Sciences, China). The temperature dependence of hysteresis loop $(P-E)$ and unipolar strain $\left(S_{\text {uni }}-E\right)$ were measured at
$1 \mathrm{~Hz}$ using a ferroelectric tester (TF2000, aixACCT, Aachen, Germany). The values of $k_{p}$ and $k_{\mathrm{t}}, k_{31}$ and $d_{31}$ were determined using disk and bar samples, respectively, by the resonant-antiresonant method. The value of $k_{33}$ was estimated by $k_{\mathrm{p}}$ and $k_{\mathrm{t}}$ using the following equation: ${ }^{33}$

$$
\left(k_{33}\right)^{2} \approx\left(k_{\mathrm{p}}\right)^{2}+\left(k_{\mathrm{t}}\right)^{2}-\left(k_{\mathrm{p}}\right)^{2}\left(k_{\mathrm{t}}\right)^{2}
$$

The room temperature XRD patterns of all as-sintered PMN-PFN-PZ-PT ceramics are shown in Fig. 1(b). All peaks can be identified to the corresponding Miller indices, which indicate the as-sintered ceramics are of pure perovskite structure. Fig. 1(b) gives the enlarged (200)-reflections in the range of $2 \theta=44^{\circ}-46^{\circ}$, which are fitted using the Lorentzian function. The (200)-reflection changes obviously with increasing PT content. When $x=0.30$, only a single $(200)_{R}$-peak is observed, indicating a rhombohedral $(\mathrm{R})$ phase; at $\mathrm{x}=0.34$, the (200)-peak splits into two peaks $(200)_{\mathrm{T}}$ and $(002)_{\mathrm{T}}$, demonstrating a tetragonal $(\mathrm{T})$ phase; while for the compositions in the range of $0.30<\mathrm{x}<0.34$, the peaks are very broad and can be fitted by three peaks: $(002)_{\mathrm{T}},(200)_{\mathrm{R}}$, and $(200)_{\mathrm{T}}$, indicating a mixture of rhombohedral and tetragonal phases. Therefore, the MPB region can be determined at $0.30<\mathrm{x}<0.34$.

Figs. 2(a) and 2(b) reveal the composition dependence of piezoelectric, dielectric, and ferroelectric properties of asexplored quaternary system at room temperature. Wellsaturated hysteresis loops were obtained at $30 \mathrm{kV} / \mathrm{cm}$ in Fig. 2(a). From Figs. 2(b1)-2(b3), it can be found that the highest piezoelectric coefficient $d_{33}$, planar electromechanical coupling $k_{\mathrm{p}}$ and dielectric permittivity $\varepsilon_{\mathrm{r}}$ appear at MPB region determined by XRD analysis. The highest $d_{33}$ and $k_{\mathrm{p}}$ were found to be $640 \mathrm{pC} / \mathrm{N}, 0.53$ at $\mathrm{x}=0.32$, while the composition on the tetragonal side of MPB $(\mathrm{x}=0.33)$ has the highest $\varepsilon_{\mathrm{r}}$ of 2630 and high $d_{33}$ of $580 \mathrm{pC} / \mathrm{N}$. Fig. 2(b4) gives the field-induced piezoelectric strain coefficient $d_{33} *=S_{\max } / E_{\max }$ ( $S_{\max }$ is the maximum strain and $E_{\max }$ is the maximum electric field, $\sim 10 \mathrm{kV} / \mathrm{cm}$ in this study) calculated from the data in Fig. 2(c), which exhibits a similar composition-dependent tendency with the $d_{33}$ measured by quasi-static piezo- $d_{33}$ 

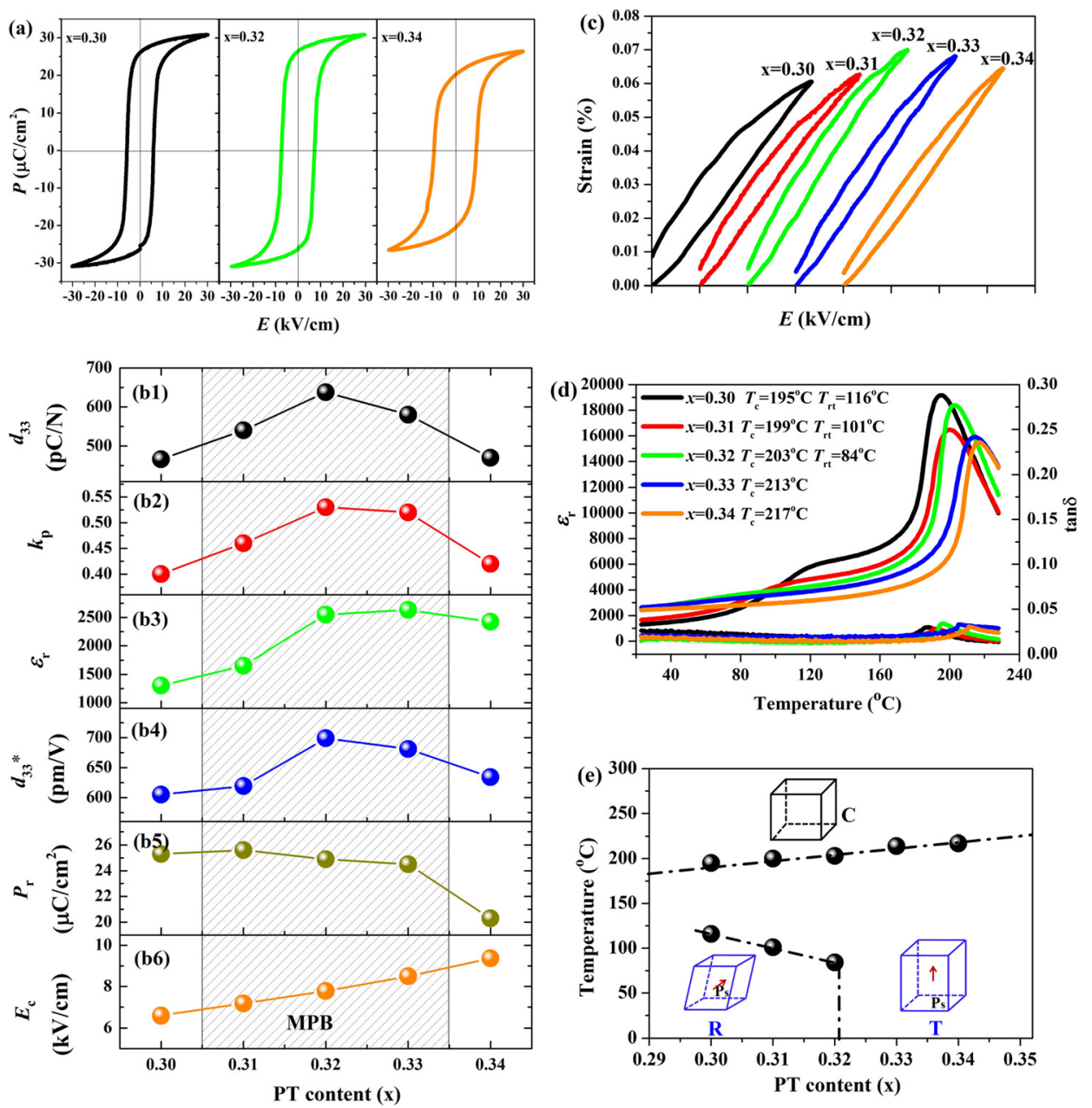

FIG. 2. (a) Hysteresis loops of $\mathrm{x}=0.30, \mathrm{x}=0.32$, and $\mathrm{x}=0.34$. (b1) Piezoelectric coefficients $d_{33}$, (b2) planar electromechanical coupling $k_{\mathrm{p}}$, (b3) dielectric permittivity $\varepsilon_{\mathrm{r}}$, (b4) field-induced piezoelectric strain coefficient $d_{33}{ }^{*}$, (b5) remnant polarization $P_{\mathrm{r}}$, (b6) coercive field $E_{\mathrm{c}}$. (c) Unipolar $S_{\text {uni }}-E$ curves at room temperature. (d) Temperature dependence of dielectric permittivity $\varepsilon_{\mathrm{r}}$ and $\tan \delta$ of poled samples. (e) Temperature-composition phase diagram of PMN-PFN-PZ-PT quaternary system. meter. The samples with MPB composition exhibit large piezoelectric coefficient $d_{33} *$ of $620 \mathrm{pm} / \mathrm{V}, 700 \mathrm{pm} / \mathrm{V}$, and $680 \mathrm{pm} / \mathrm{V}$ for $\mathrm{x}=0.31, \mathrm{x}=0.32$, and $\mathrm{x}=0.33$, respectively. The remnant polarization $P_{\mathrm{r}}$ are almost stable in the order of $25 \mu \mathrm{C} / \mathrm{cm}^{2}$ for both R phase and MPB compositions, while an abrupt decrease of $P_{\mathrm{r}}=20 \mu \mathrm{C} / \mathrm{cm}^{2}$ is observed for T phase composition at $\mathrm{x}=0.34$. This phenomenon can be explained by the more equivalent directions of domain states in R/MPB phase and the clamping of domain wall in $\mathrm{T}$ phase. ${ }^{34}$ Fig. 2(b6) shows that the coercive field $E_{\mathrm{c}}$ increases with increasing PT content, ranging from 6.4 to $9.4 \mathrm{kV} / \mathrm{cm}$, attributing to the increased tetragonal component.

The temperature dependence of dielectric permittivity $\varepsilon_{\mathrm{r}}$ and $\tan \delta$ at $1 \mathrm{kHz}$ with various PT contents are presented in Fig. 2(d). The dielectric losses of all compositions are around 0.015 at room temperature. Two dielectric anomalies can be observed for R-rich samples, being related to the rhombohedral-tetragonal ferroelectric phase transition temperature $T_{\mathrm{rt}}$ and ferroelectric-paraelectric phase transition temperature $T_{\mathrm{c}}$, respectively. Of particular significance is that the dielectric permittivity exhibits an improved temperature stability with increasing PT content, and there is no ferroelectric phase transition being observed prior to Curie temperature for MPB composition $\mathrm{x}=0.33$. Based on the results of temperature-dependent dielectric permittivity, an isothermal phase diagram of PMN-PFN-PZ-PT system is established and plotted as a function of PT content, as shown in Fig. 2(e). It is evident that $T_{\mathrm{c}}$ enhances linearly from $195^{\circ} \mathrm{C}$ to $217^{\circ} \mathrm{C}$ with increasing PT content, due to the high $T_{\mathrm{c}} \approx 490^{\circ} \mathrm{C}$ of PT. The rhombohedral-tetragonal phase transition temperature $T_{\mathrm{rt}}$ deceases and finally disappears when the phase structure transforms from rhombohedral-rich phase to tetragonal-rich phase. An enhancement of $T_{\mathrm{rt}}$ about $30^{\circ} \mathrm{C}$ is achieved for the quaternary system, when compared with that of PMN-PT counterpart, rising from $84^{\circ} \mathrm{C}$ to about $116^{\circ} \mathrm{C}$. Compared with the previously reported PMN-PFN-PZ-PT system with 5\% PZ, ${ }^{31}$ the compositions with $10 \% \mathrm{PZ}$ at MPB process comparable piezoelectric coefficient and electromechanical coupling, but higher $T_{\mathrm{c}} / T_{\mathrm{rt}}$, indicating a broader usage temperature range.

To evaluate the thermal stability performance, the unipolar strains $S_{\text {uni }}-E$ were measured as a function of temperature. Fig. 3(a) is an example of the temperature-dependent unipolar strain for $\mathrm{x}=0.33$ measured at $10 \mathrm{kV} / \mathrm{cm}$, in which typical linear $S_{\text {uni }}-E$ curves can be observed. The $d_{33} *$ values derived from the unipolar strains of all compositions are plotted in Fig. 3(b). For samples with lower PT content, $d_{33}{ }^{*}$ is found to increase quickly with increasing temperature, reaching maximum value at their corresponding $T_{\mathrm{rt}}$. With increasing PT content, the variation of $d_{33}{ }^{*}$ becomes smaller and the inverse temperature decreases from $115^{\circ} \mathrm{C}$ for $\mathrm{x}=0.30$ to below room temperature when $\mathrm{x} \geqslant 0.34$. Of particular interest is that high $d_{33} *$ value with a minimal temperature-dependent variation is obtained for $\mathrm{x}=0.33$, in the temperature range of $25-165^{\circ} \mathrm{C}$. Fig. 3(c) shows the normalized piezoelectric value $d_{33}{ }^{*} \mathrm{~T} / d_{33}{ }^{*}$ RT as a function of temperature for different ceramic systems. It should be noted 

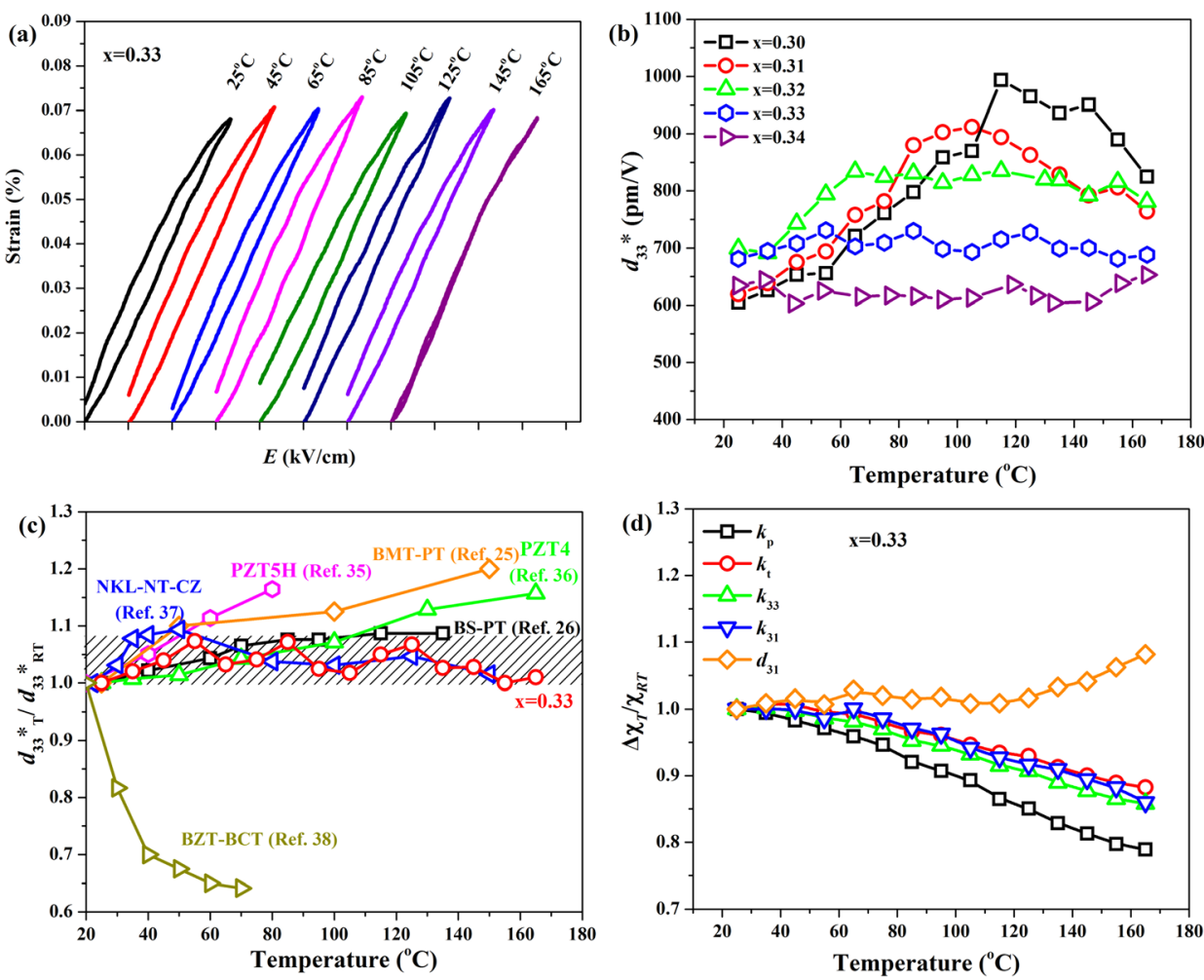

FIG. 3. (a) Temperature-dependent unipolar strain for $\mathrm{x}=0.33$. (b) Temperature dependence of $d_{33} *$ for ceramics with different PT contents. (c) Comparison of temperature dependence of piezoelectric coefficients for various piezoceramics as normalized to their room temperature values $d_{33}{ }_{\mathrm{T}} / d_{33}{ }{ }_{\mathrm{RT}}$. The data for PZT5H, ${ }^{35}$ PZT $4,{ }^{36}$ BMN-PT, ${ }^{25}$ BS-PT, ${ }^{26}$ NKL-NT-CZ, ${ }^{37}$ and BZT-50BCT ${ }^{38}$ are derived from figures in the respective references. The piezoelectric coefficient of BZT-50BCT measured by a commercial Berlingcourt-type $d_{33}$ meter. (d) Temperature dependences of $k_{\mathrm{p}}, k_{\mathrm{t}}, k_{33}, k_{31}$, and $d_{31}$ normalized to their room temperature values for $\mathrm{x}=0.33$. that the variation of $d_{33} *$ for PMN-PFN-PZ-PT ceramics with $\mathrm{x}=0.33$ is less than $8 \%$ in the investigated temperature range, much lower than those of commercial PZT5H $(>20 \%)^{35}$ and PZT4 $(\sim 15 \%)^{36}$ ceramics, and outperforms slightly compared with BMT-PT ${ }^{25}$ and BST-PT ${ }^{26}$ which possess much higher Curie temperature of $>300{ }^{\circ} \mathrm{C}$. In addition, $\quad\left(\mathrm{Na}_{0.49} \mathrm{~K}_{0.49} \mathrm{Li}_{0.02}\right)\left(\mathrm{Nb}_{0.8} \mathrm{Ta}_{0.2}\right) \mathrm{O}_{3}-0.05 \mathrm{CaZrO}_{3}$ (NKL-NT-CZ) ${ }^{37}$ lead-free ceramics exhibit a comparable $d_{33}{ }^{*}$ variation of $\sim 10 \%$ in the studied temperature range, however, the value of $d_{33} *$ is $320 \mathrm{pm} / \mathrm{V}$, being only half of that of $\mathrm{x}=0.33$; while $\mathrm{Ba}\left(\mathrm{Ti}_{0.8} \mathrm{Zr}_{0.2}\right) \mathrm{O}_{3}-50\left(\mathrm{Ba}_{0.7} \mathrm{Ca}_{0.3}\right) \mathrm{TiO}_{3}$ $(\mathrm{BZT}-50 \mathrm{BCT})^{38}$ has much lower Curie temperature and its $d_{33}$ decreases to nearly $60 \%$ of the room temperature value when temperature increases to $70^{\circ} \mathrm{C}$. The high field-induced piezoelectric strain coefficient and excellent temperature stability of $\mathrm{x}=0.33$ make it promising for temperature-insensitive actuator devices.

To further evaluate the temperature stability of $\mathrm{x}=0.33$, the value of $k_{\mathrm{p}}, k_{\mathrm{t}}, k_{33}, k_{31}$, and $d_{31}$ were calculated/estimated as a function of temperature. As shown in Fig. 3(d), $k_{\mathrm{p}}, k_{\mathrm{t}}$, $k_{33}$, and $k_{31}$ decrease with increasing temperature, with a reduction ranging from $10 \%$ to $20 \%$. While the $d_{31}$ exhibits high temperature stability with a variation of less than $9 \%$, similar to that of piezoelectric coefficient $d_{33} *$, which further confirms that $\mathrm{x}=0.33$ processes high temperature stability of piezoelectric properties.

The results provide strong evidence that high temperature stability of piezoelectric coefficient can be achieved for $\mathrm{x}=0.33$, which can be explained by the phenomenological relationship of electrostriction in ferroelectrics. Generally, electrostrictive coefficient $Q$, dielectric permittivity $\varepsilon_{\mathrm{r}}$, and polarization $P$ contribute to $d_{33}$, following the equation: ${ }^{39}$

$$
d_{33}{ }^{*} \propto Q \varepsilon_{0} \varepsilon_{\mathrm{r}} P
$$

where $\varepsilon_{0}$ is vacuum permittivity. $P$ approximately equals to the remnant polarization $P_{\mathrm{r}}$ for ferroelectric ceramics. The electrostrictive $Q$ is insensitive to temperature, ferroelectric phase structure, and phase transition in perovskite materials when compared with the strong temperature dependent dielectric properties. ${ }^{40}$ The equation above suggests that the variation of $d_{33} *$ is mainly related to $\varepsilon_{\mathrm{r}} \times P$. The temperature-dependent maximum polarization $P_{\max }$, remnant polarization $P_{\mathrm{r}}$, coercive field $E_{\mathrm{c}}$, and dielectric permittivity $\varepsilon_{\mathrm{r}}$ for $\mathrm{x}=0.30$ and $\mathrm{x}=0.33$ are given in Figs. 4(a) and 4(b), respectively. $P_{\max }$ and $P_{\mathrm{r}}$ decrease monotonically with increasing temperature, resulting from the so-called pyroelectric effect, ${ }^{41}$ and $E_{\mathrm{c}}$ exhibits the same trend, due to the easier domain wall motion at elevated temperature. On the contrary, $\varepsilon_{\mathrm{r}}$ increases with increasing temperature for both compositions. An abrupt enhancement of $\varepsilon_{\mathrm{r}}$ near the ferroelectric phase transition temperature can be found for $\mathrm{x}=0.30$; while $\varepsilon_{\mathrm{r}}$ is much flatter for $\mathrm{x}=0.33$, due to the smeared free energy barrier between rhombohedral and tetragonal phases. The value of $\varepsilon_{\mathrm{r}} \times P$ for $\mathrm{x}=0.30$ is found to increase with increasing temperature, with inversion point occurring around $115^{\circ} \mathrm{C}$, due to the ferroelectric phase transition, which is consistent with the evolution of $d_{33} *$, as depicted in Fig. 4(a). Of particular importance is that the value of $\varepsilon_{\mathrm{r}} \times P$ for $\mathrm{x}=0.33$ is nearly temperature-independent from $25^{\circ} \mathrm{C}$ to $165^{\circ} \mathrm{C}$, as shown in Fig. 4(b), accounting for the high temperature stability of $d_{33}{ }^{*}$. From the phenomenological descriptions above, it can be concluded that the origin of temperatureinsensitive field-induced $d_{33} *$ may result from the counterbalance of the ascending dielectric permittivity and descending polarization with increasing temperature. Thus, if the dielectric permittivity anomaly near the ferroelectric phase transition temperature for MPB compositions is shifted or smeared by composition tuning, to achieve a stable value of $\varepsilon_{\mathrm{r}} \times P$, a temperature-insensitive $d_{33} *$ can be expected, this is the case 

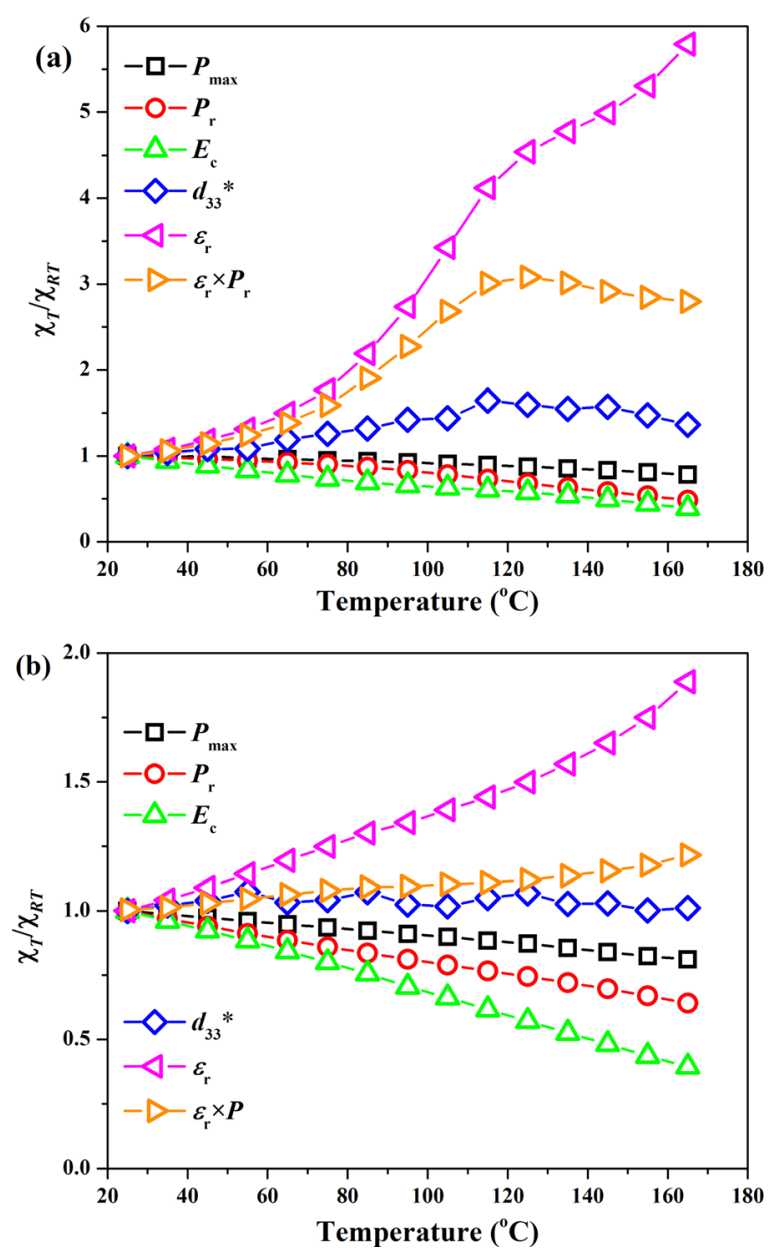

FIG. 4. Temperature dependence of various parameters, $\chi_{T} / \chi_{R T}$ stands for $P_{\max }, P_{\mathrm{r}}, E_{\mathrm{c}}, d_{33^{*}}, \varepsilon_{\mathrm{r}}$ and $\varepsilon_{\mathrm{r}} \times P_{\mathrm{r}}$ for (a) $\mathrm{x}=0.30$ and (b) $\mathrm{x}=0.33$, respectively.

for $\mathrm{x}=0.33$. Otherwise, a $d_{33}{ }^{*}$ peak will exist at the phase transition temperature, which is the phenomenon of $x=0.30$.

In summary, PMN-PFN-PZ-PT ceramics with compositions near MPB were prepared, which exhibit high piezoelectric coefficient near MPB, with $d_{33}=640 \mathrm{pC} / \mathrm{N}$ and 580 $\mathrm{pC} / \mathrm{N}$ at $\mathrm{x}=0.32$ and $\mathrm{x}=0.33$, respectively. Of particular importance is that the composition of $\mathrm{x}=0.33$ exhibited high field-induced piezoelectric strain coefficient $d_{33} *$ of $680 \mathrm{pm} / \mathrm{V}$, with a minimal temperature-dependent variation being on the order of $<8 \%$ in the temperature range of $25-165^{\circ} \mathrm{C}$ which is further confirmed by $d_{31}$, making it promising for actuator applications demanding good temperature stability. It is supposed that by shifting or smearing the dielectric permittivity anomaly near the ferroelectric phase transition temperature for MPB compositions through composition tuning, a temperature-insensitive $d_{33} *$ can be expected, according to Eq. (1).

The authors from Tsinghua University acknowledge the National Basic Research Program of China (Grant No. 2013CB632900), the National Natural Science Foundation of China (Nos. 50972071 and 51172118), Tsinghua University Initiative Scientific Research Program (Grant No. 20131089218), and the funds of State Key Laboratory of New Ceramics and Fine Processing, Tsinghua University, Beijing 100084, China. The author (Nengneng Luo) wishes to acknowledge the support from the China Scholarship Council.

${ }^{1}$ S. E. Park and T. R. Shrout, J. Appl. Phys. 82, 1804 (1997).

${ }^{2}$ G. Liu, W. H. Jiang, J. Q. Zhu, and W. W. Cao, Appl. Phys. Lett. 99, 162901 (2011).

${ }^{3}$ S. J. Zhang and F. Li, J. Appl. Phys. 111, 031301 (2012).

${ }^{4}$ L. E. Cross, Ferroelectrics 76, 241 (1987).

${ }^{5}$ Z. Y. Feng, X. Y. Zhao, and H. S. Luo, J. Appl. Phys. 100, 024104 (2006).

${ }^{6}$ C. Augier, M. PhamThi, H. Dammak, and P. Gaucher, J. Eur. Ceram. Soc. 25, 2429 (2005).

${ }^{7}$ N. Yasuda, H. Ohwa, M. Kume, K. Hayashi, Y. Hosono, and Y. Yamashita, J. Cryst. Growth 229, 299 (2001).

${ }^{8}$ N. Yasuda, H. Ohwa, M. Kume, Y. Hosono, Y. Yamashita, S. Ishino, H. Terauchi, M. Iwata, and Y. Ishibashi, Jpn. J. Appl. Phys., Part 1 40, 5664 (2001).

${ }^{9}$ S. J. Zhang, L. Lebrun, S. Rhee, C. Randall, and T. R. Shrout, Appl. Phys. Lett. 81, 892 (2002).

${ }^{10}$ Y. Yamashita, Jpn. J. Appl. Phys., Part 1 33, 4652 (1994).

${ }^{11}$ Y. Hosono, Y. Yamashita, H. Sakamoto, and N. Ichinose, Jpn. J. Appl. Phys., Part 1 41, L1240 (2002).

${ }^{12}$ G. S. Xu, K. Chen, D. F. Yang, and J. B. Li, Appl. Phys. Lett. 90, 032901 (2007).

${ }^{13}$ D. B. Lin, Z. R. Li, F. Li, Z. Xu, and X. Yao, J. Alloys Compd. 489, 115 (2010).

${ }^{14}$ F. Li, S. J. Zhang, Z. Xu, X. Y. Wei, J. Luo, and T. R. Shrout, J. Am. Ceram. Soc. 93, 2731 (2010).

${ }^{15} \mathrm{~F}$. Li, S. J. Zhang, Z. Xu, X. Y. Wei, J. Luo, X. Y. Wei, and T. R. Shrout, Appl. Phys. Lett. 97, 252903 (2010).

${ }^{16}$ Z. G. Xia and Q. Li, J. Phys. D: Appl. Phys. 40, 7826 (2007).

${ }^{17}$ S. J. Zhang, S. M. Lee, D. H. Kim, H. Y. Lee, and T. R. Shrout, Appl. Phys. Lett. 90, 232911 (2007).

${ }^{18}$ Z. G. Xia, Q. Li, and S. F. Zhang, Solid State Commun. 145, 38 (2008).

${ }^{19}$ S. J. Zhang, S. M. Lee, D. H. Kim, H. Y. Lee, and T. R. Shrout, Appl. Phys. Lett. 93, 122908 (2008).

${ }^{20}$ Y. Hosono, K. Harada, Y. Yamashita, M. Dong, and Z. G. Ye, Jpn. J. Appl. Phys., Part 1 39, 5589 (2000).

${ }^{21}$ R. E. Eitel, C. A. Randall, T. R. Shrout, P. W. Rehrig, W. Hackenberger, and S. E. Park, Jpn. J. Appl. Phys., Part 1 40, 5999 (2001).

${ }^{22}$ T. P. Comyn, S. P. McBirde, and A. J. Bell, Mater. Lett. 58, 3844 (2004).

${ }^{23}$ S. J. Zhang, R. Xia, C. A. Randall, and T. R. Shrout, J. Mater. Res. 20, 2067 (2005).

${ }^{24}$ S. M. Choi, C. J. Stringer, T. R. Shrout, and C. A. Randall, J. Appl. Phys. 98, 034108 (2005).

${ }^{25}$ Q. Zhang, Z. R. Li, F. Li, Z. Xu, and X. Yao, J. Am. Ceram. Soc. 93, 3330 (2010).

${ }^{26}$ T. Leist, J. Chen, W. Jo, E. Aulbach, J. Suffner, and J. Rödel, J. Am. Ceram. Soc. 95, 711 (2012).

${ }^{27}$ S. J. Zhang and T. R. Shrout, IEEE Trans. Ultrason. Ferroelectr. Freq. Control 57, 2138 (2010).

${ }^{28}$ J. Tian, P. D. Han, X. L. Huang, H. X. Pan, J. F. Carroll III, and D. A. Payne, Appl. Phys. Lett. 91, 222903 (2007).

${ }^{29}$ F. Li, S. J. Zhang, Z. Xu, X. Y. Wei, and T. R. Shrout, Adv. Funct. Mater. 21, 2118 (2011).

${ }^{30}$ N. N. Luo, Y. Y. Li, Z. G. Xia, and Q. Li, CrystEngComm 14, 4547 (2012).

${ }^{31}$ N. N. Luo, Q. Li, Z. G. Xia, and X. C. Chu, J. Am. Ceram. Soc. 95, 3246 (2012).

${ }^{32}$ IEEE Standards on Piezoelectricity, ANSI/IEEE Standard, New York (1987).

${ }^{33}$ S. J. Zhang, E. F. Alberta, R. E. Eitel, C. A. Randall, and T. R. Shrout, IEEE Trans. Ultrason. Ferroelectr. Freq. Control 52, 2131 (2005).

${ }^{34}$ L. Jin, F. Li, and S. J. Zhang, J. Am. Ceram. Soc. 97, 1 (2014).

${ }^{35}$ D. Wang, Y. Fotinich, and G. P. Carman, J. Appl. Phys. 83, 5342 (1998).

${ }^{36}$ Y. Sait, H. Takao, T. Tani, T. Nonoyama, K. Takatori, T. Homma, T. Nagaya, and M. Nakamura, Nature 432, 84 (2004).

${ }^{37}$ K. Wang, F. Z. Yao, W. Jo, D. Gobeljic, V. V. Shvartsman, D. C. Lupascu, J. F. Li, and J. Rödel, Adv. Funct. Mater. 23, 4079 (2013).

${ }^{38}$ W. F. Liu and X. B. Ren, Phys. Rev. Lett. 103, 257602 (2009).

${ }^{39}$ J. Kuwata, K. Uchino, and S. Nomura, Jpn. J. Appl. Phys., Part 1 19, 2099 (1980).

${ }^{40}$ F. Li, L. Jin, Z. Xu, and S. J. Zhang, Appl. Phys. Rev. 1, 011103 (2014).

${ }^{41}$ X. Li, S. G. Lu, X. Z. Chen, H. Gu, X. S. Qian, and Q. M. Zhang, J. Mater. Chem. C 1, 23 (2013). 